Article

\title{
Adsorption Behavior of Magnetic Carbon-Supported Metal Nickel for the Efficient Dye Removal from Water
}

\author{
Beifeng Lv ${ }^{1}{ }^{\mathbb{D}}$, Jingjing $\mathrm{Xu}^{2}$, Haibo Kang ${ }^{3}$, Pengfei Liang ${ }^{2}$, Wei Wang ${ }^{1}{ }^{\mathbb{D}}$ and Feifei Tao ${ }^{2, *}$ \\ 1 School of Civil Engineering, Shaoxing University, Shaoxing 312000, China; 20020852047@usx.edu.cn (B.L.); \\ wellswang@usx.edu.cn (W.W.) \\ 2 School of Chemistry and Chemical Engineering, Shaoxing University, Shaoxing 312000, China; \\ xuliuri888@163.com (J.X.); pf13909425848@163.com (P.L.) \\ 3 School of Civil Engineering, College of Transportation Engineering, Nanjing Tech University, \\ Nanjing 210009, China; nobody@njtech.edu.cn \\ * Correspondence: feifeitao@usx.edu.cn
}

check for

updates

Citation: Lv, B.; Xu, J.; Kang, H.;

Liang, P.; Wang, W.; Tao, F.

Adsorption Behavior of Magnetic

Carbon-Supported Metal Nickel for

the Efficient Dye Removal from

Water. Int. J. Environ. Res. Public

Health 2022, 19, 1682. https://

doi.org/10.3390/ijerph19031682

Academic Editors: Aneta Michna,

Maria Morga and Dominik Kosior

Received: 2 January 2022

Accepted: 30 January 2022

Published: 1 February 2022

Publisher's Note: MDPI stays neutral with regard to jurisdictional claims in published maps and institutional affiliations.

Copyright: (C) 2022 by the authors. Licensee MDPI, Basel, Switzerland. This article is an open access article distributed under the terms and conditions of the Creative Commons Attribution (CC BY) license (https:// creativecommons.org/licenses/by/ $4.0 /)$.

\begin{abstract}
Magnetic carbon-supported metal nickel has been successfully synthesized by solvothermal method and heat treatment for highly effective adsorption of various reactive dyes. Structure characterization and composition analysis demonstrated that the metal nickel nanoparticles with the size of 1-2 nm were embedded into the pore of carbon spheres. It is helpful to prevent the agglomeration and falling off of metal nickel nanoparticles on the surface of carbon spheres. The adsorption performance of the carbon-supported metal nickel nanospheres for reactive brilliant yellow R-4GLN was studied by changing the $\mathrm{pH}$ value and initial concentration of the solution, adsorption time, adsorption temperature, and the amount of adsorbent. The carbon-supported metal nickel showed fast and efficient adsorption activity. After $5 \mathrm{~min}$ of adsorption, the removal efficiency of $10 \mathrm{~mL} 25 \mathrm{mg} \cdot \mathrm{mL}^{-1}$ reactive brilliant yellow R-4GLN was close to $100 \%$. The carbon-supported metal nickel composite was reused 20 times, and the removal efficiency of dye remained above $98 \%$. It also showed good adsorption performance on various reactive dyes with wide universality, which has a certain adsorption effect on most dyes with a high utilization value in wastewater treatment.
\end{abstract}

Keywords: template method; solvothermal method; carbon-supported metal nickel; adsorption performance

\section{Introduction}

With the rapid growth of population and economy, environmental pollution has been an important problem affecting people's healthy life. Water sources are becoming increasingly polluted due to the excessive discharge of colored wastewater from textile, paper, rubber, and other industries [1,2]. Therefore, efficient removal of colored wastewater is very important to alleviate environmental pollution [3-5]. Various technologies, such as ion-exchange [6], ozonation [7], chemical precipitation [8], electrochemical treatment [9], membrane separation [10], photocatalysis [11], and adsorption [12], have been developed to purify wastewater. Among then, adsorption has been considered economical and reliable due to its feasibility, easy operation, low cost, recyclability, and high efficiency [12-14].

The composite composed of carbon materials and magnetic metal has been proven to be used as excellent adsorbent to purify wastewater [15], due to the advantages of large specific surface area, easy regulation of size and morphology, stable performance, and easy recycling. Carbon materials from various carbon sources have been widely applied as adsorbents for the removal of inorganic and organic pollutions from water [16-18]. However, the separation and recovery of carbon materials is difficult, which limits its application. So as a new type of magnetic nanomaterial, the carbon-supported metal nickel composite also exhibits the potential application as adsorbent in wastewater treatment [19]. 
There are many preparation methods of metal nanoparticles, and the preparation of nano nickel powder mainly adopting the steam-condensation method, chemical vapor deposition method, precipitation method, sol-gel method, ionic liquid method, and solid-phase redox method, etc. [20]. Wu et al. [21] successfully synthesized spherical pure metal nickel nanoparticles by chemical reduction of nickel chloride with hydrazine at room temperature without any protective agent or inert gas, and the obtained nickel nanoparticles could be separated in solid state and stabilized in the atmosphere for several months. Chou et al. [22] prepared nickel nanoparticles by chemical reduction method under a controlled $\mathrm{pH}$ environment and also characterized the product. Meshkani et al. [23] prepared a series of nickel catalysts with different contents of supported mesoporous spherical $\mathrm{SiO}_{2}$ by sol-gel method, and the experimental results showed that the samples prepared with 55\% nickel performed the best in the temperature and stability tests. Ádám et al. [24] used ultrasound-assisted reduction method to prepare nickel nanoparticles and carried out physical and chemical characterization. The experimental results showed that the ultrasonic prepared nickel nanoparticles had good catalytic activity. Liu Guang et al. [25] for the first time synthesized a graphene hybrid modified ultrafine nickel nanoparticle through in-situ chemical meteorological deposition to improve the wettability between metal and carbon nanophases. Sagadevan et al. [26] prepared nickel ferrite nanoparticles by co-precipitation method and characterized them. Ragupathi et al. [27] synthesized nickel aluminate nanoparticles by microwave combustion method (MCM) and found that nickel aluminate nanoparticles prepared by MCM had higher surface area and lower grain size than that prepared by conventional combustion method. Guillén-Bonilla et al. [28] synthesized nickel formic acid-resistant nanoparticles by microwave-assisted wet chemical method, which is a very economical and effective way to obtain the size of nanoparticles. Aghari et al. [29] synthesized nickel magnetic mirror nanoparticles by a convenient chemical method and studied their antibacterial effect on $S$. aureus and E. coli bacteria. Krebsz et al. [30] synthesized recently carbon microsphere-supported metallic nickel nanoparticles by carbonizing a polystyrene-based cation exchange resin loaded with nickel ions. Nanoparticles showed high catalytic activity in nitrophenol reduction.

Due to the characteristics of low redox potential, active properties, magnetic properties, and easy agglomeration of nickel, it is still difficult to prepare nano-nickel powder with small particle size, uniform dispersion, and good performance [31]. The template synthesis method allows the generated nanoparticles to be assembled in a certain way, so as to obtain supramolecular nanomaterials with specific morphologies [32]. There are relatively few reports on the preparation of nano metal powders by this method, especially for carbonsupported metal powder with magnetic properties. The physical and chemical properties of nanomaterials largely depend on their size and shape. Due to the special physical and chemical properties of nickel, nickel and its compounds have been widely used in chemical, aviation, military, and construction engineering fields [33-35], but there are few reports on water pollution treatment in the field of environmental geotechnical engineering. Therefore, the preparation of carbon-supported metal nickel and its application in water treatment have become the focus of this thesis.

In this paper, a simple template method combined with annealing treatment is proposed to synthesize magnetic spherical carbon-supported nickel. UV-vis spectrometer is used to study the adsorption performance of carbon-supported metal nickel for reactive dyes, by changing the $\mathrm{pH}$ value and initial concentration of the solution, adsorption temperature, adsorption time, and the amount of adsorbent to explore the best conditions for the adsorption of reactive brilliant yellow R-4GLN by carbon-supported metal nickel and its universality. Here the introduction of a large number of metal nickel with 1-2 nm in the surface of carbon spheres improves the specific surface area, exhibits the paramagnetic properties for the separation and recovery of the adsorbent, and enhances the adsorption performance. 


\section{Experimental Section}

\subsection{Preparation of Carbon Spheres}

Carbon spheres with size of about $200 \mathrm{~nm}$ were prepared following literature methods with some modifications [36]. $2.0 \mathrm{~g}$ of anhydrous glucose was dispersed in $20 \mathrm{~mL}$ of distilled water, and then stirred until the glucose was completely dissolved. The above solution was transferred to a stainless-steel autoclave and kept at $180{ }^{\circ} \mathrm{C}$ for $8 \mathrm{~h}$. After the reaction, the autoclave was cooling to room temperature naturally, and the black powder was centrifuged and washed with a large amount of distilled water. Then it was put in an oven to dry at $80{ }^{\circ} \mathrm{C}$ for about $10 \mathrm{~h}$ to obtain the carbon sphere template for preparing the carbon-supported nickel composite.

\subsection{Preparation of Carbon-Supported Nickel Composite}

Carbon-supported metal nickel composite was prepared on basis of previously reported work with some modifications [36]. $0.06 \mathrm{~g}$ of $\mathrm{NiCl}_{2} \cdot 6 \mathrm{H}_{2} \mathrm{O}$ and $0.10 \mathrm{~g}$ of the prepared carbon spheres were dispersed in the mixed solution of $10 \mathrm{~mL}$ distilled water and $10 \mathrm{~mL}$ absolute ethanol. After the ultrasonic treatment for $10 \mathrm{~min}$, the above suspension was added by $2.52 \mathrm{~g}$ of $\mathrm{C}_{2} \mathrm{H}_{2} \mathrm{O}_{4} \cdot 2 \mathrm{H}_{2} \mathrm{O}$, which was placed in ultrasound for another $2 \mathrm{~h}$ and stirred for $10 \mathrm{~h}$ at the room temperature. The obtained suspension was centrifuged and washed with distilled water five times, and then it was placed in an oven to dry at $80{ }^{\circ} \mathrm{C}$ overnight. The product was put into the tubular furnace and kept at $350{ }^{\circ} \mathrm{C}$ for $2 \mathrm{~h}$ for annealing treatment under the protection of $\mathrm{N}_{2}$ to obtain the carbon-supported nickel composite.

\subsection{Characterization Methods}

The morphology of the samples was characterized by scanning electron microscopy (SEM, JSM-6360LV, from Japan, JEOL) and high-resolution transmission electron microscope (HRTEM, JEM-2100F, from Japan, JEOL). The energy dispersive X-ray spectroscopy (EDS) was used to determine the elements on an energy spectrum (X-act, from UK, Oxford). The crystal structures of the products were characterized by X-ray diffractometer (XRD, XRD-6000, from Netherlands, Empyrean, Cu K $\alpha \lambda=0.15406 \mathrm{~nm}$ ). The content of metal nickel in the composite was determined by inductively coupled plasma atomic emission spectrometry (ICP-AES, from USA, Leeman) The Brunauer-Emmett-Teller (BET) surface areas and porosities were measured by $\mathrm{N}_{2}$ adsorption-desorption isotherms on an Empyrean apparatus from USA Micromeritics. Magnetic hysteresis curve was evaluated using a vibrating sample magnetometer (VSM attachment on PPMS Dynacool System, from USA, Quantum Design International) at room temperature.

\subsection{Adsorption Experiments}

To investigate the adsorption properties of the as-prepared samples, $10 \mathrm{mg}$ of the powder was dispersed in $10 \mathrm{~mL} 25 \mathrm{mg} \cdot \mathrm{L}^{-1}$ of reactive dye solution (reactive brilliant yellow R-4GLN, reactive dark blue B-2GLN or reactive red R-4BD) as the dye wastewater by the ultrasound treatment for at least $2 \mathrm{~min}$. There was no equilibrium time spent before starting the adsorption tests. After each period of time, $5 \mathrm{~mL}$ of the suspension was taken out and centrifuged. To obtain the concentration of dye solution, the obtained supernatant was evaluated using a calibration curve plotted with UV-vis spectrometer (UV1800TC), and the absorbance at the maximum absorption wavelength of each dye was used to calculate the removal efficiency. To ensure the accuracy of the measurement, each experimental data is obtained by repeating three times, and the average value of the three data is used.

$$
\text { Removal } \%=\left(A_{0}-A\right) / A_{0} \times 100 \%
$$

where, $A_{0}$ represents the absorbance of the reactive dye at the maximum absorption wavelength before adsorption, and $A$ represents the absorbance of the reactive dye at the maximum absorption wavelength after adsorption. 
The adsorption capacity and equilibrium constant are calculated as follows:

$$
\begin{gathered}
q=\left(C_{0}-C_{\mathrm{e}}\right) * V / m \\
C_{\mathrm{e}} / q=1 /\left(K * q_{\mathrm{m}}\right)+C_{\mathrm{e}} / q_{\mathrm{m}}
\end{gathered}
$$

where, $q$ represents the quantity of dye per mass of adsorbate at equilibrium $(\mathrm{mg} / \mathrm{g}) ; C_{0}$ represents the initial concentration of the solution $(\mathrm{mg} / \mathrm{L}) ; C_{\mathrm{e}}$ represents the concentration of the dye solution at equilibrium $(\mathrm{mg} / \mathrm{L})$; $\mathrm{V}$ represents the volume of the adsorption solution $(\mathrm{mL}) ; m$ represents the amount of adsorbent $(\mathrm{g}) ; q_{\mathrm{m}}$ represents the maximum Langmuir monolayer adsorption capacity $(\mathrm{mg} / \mathrm{g})$; and $K$ represents the Langmuir constant $(\mathrm{L} / \mathrm{mg})$.

\subsection{Cyclic Stability Measurement}

To make clear the cyclic stability of the carbon-supported metal nickel composite for the adsorption of reactive brilliant yellow R-4GLN, 20 consecutive adsorption test cycles were conducted at the same experimental conditions. After each cycle, the recovered composite was washed with a large amount of distilled water, dried at $80^{\circ} \mathrm{C}$, and heat treated at $350{ }^{\circ} \mathrm{C}$ for $2 \mathrm{~h}$ for the desorption of dye molecules.

\section{Results and Discussion}

\subsection{Morphology and Structure Characterization}

Figure 1 shows the SEM and TEM images of carbon spheres and carbon-supported metal nickel. As shown in Figure 1a, there are a large number of spherical particles with the uniform diameter of 200-300 nm, which can be proved by HRTEM image (Figure 1b). It is further found that the spheres intersect with each other, resulting in poor dispersion. From the further enlarge HRTEM image (inset of Figure 1b), no lattice fringe can be observed, indicating that the product is weakly crystalline or amorphous carbon. When the metal nickel is loaded on the carbon spheres, the obtained product exhibits the morphology and size similar to carbon spheres (Figure 1c). Based on the further observation from the HRTEM image (Figure 1d), it is found that the spheres are complete and don't intersect with each other, indicating the good dispersion. From the enlarge HRTEM image (inset of Figure 1d), many black dots are scattered on the surface of sphere independently of each other, indicating that metal nickel nanodots with the diameter of 1-2 nm embed in the pore of the spheres, which is further proved by the element mapping analysis of $\mathrm{C}$ and $\mathrm{Ni}$ elements over the carbon-supported metal nickel (Figure $2 \mathrm{a}-\mathrm{c}$ ). The Ni metal displays the element mapping similar to $\mathrm{C}$ element, indicating that the metal nickel nanodots are evenly distributed on the surface of carbon spheres. Moreover, based on the investigation of the surface composition by EDS (Figure 2d), it is found that the obtained sample consists of C and Ni elements, further confirming the HRTEM results. And the content of Ni elements is $12.81 \mathrm{wt} \%$, which is similar to $12.90 \mathrm{wt} \%$ calculated by the addition during the reaction and $12.72 \mathrm{wt} \%$ from ICP-AES. The unique structure of the carbon-supported metal nickel can effectively protect metal nickel from oxidation. 

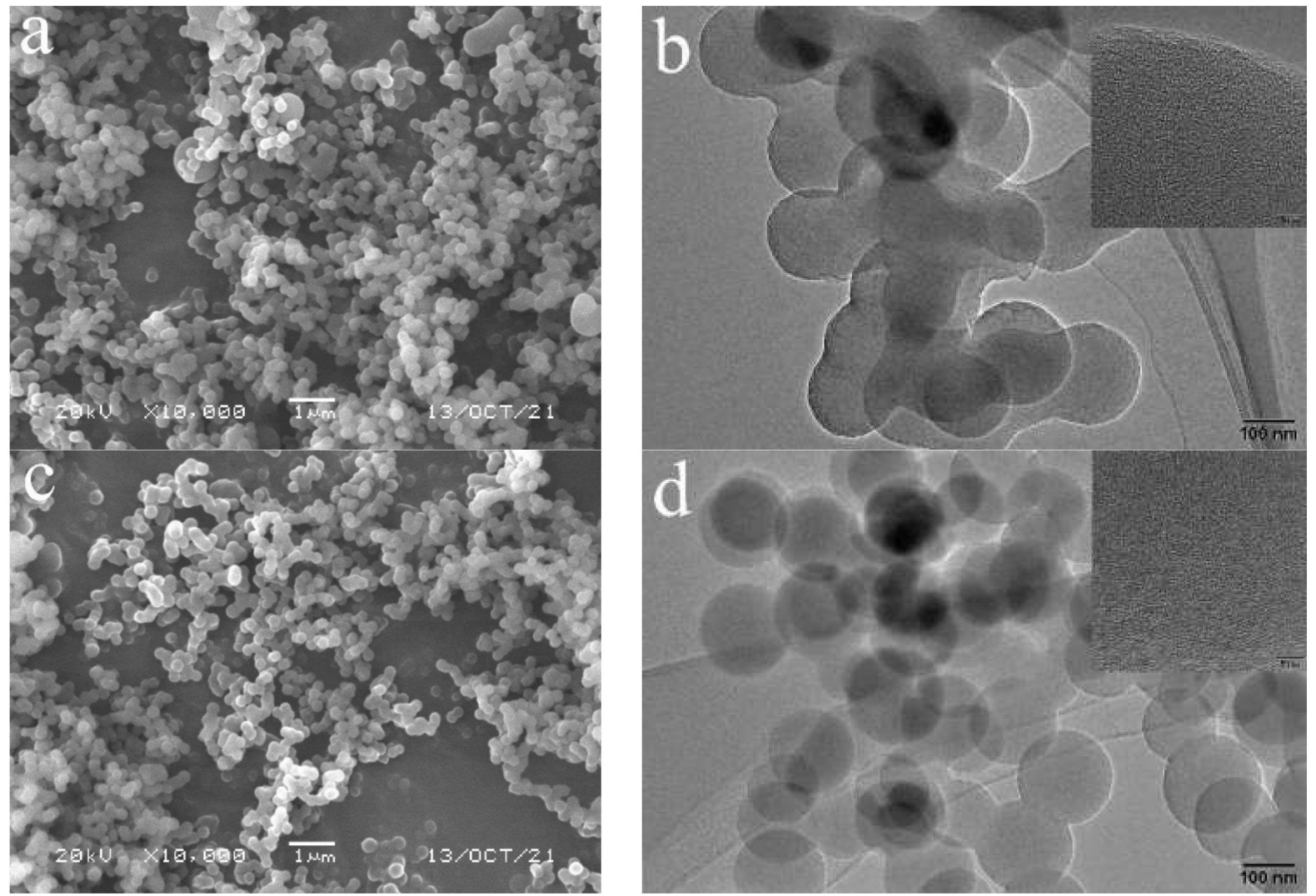

Figure 1. SEM $(\mathbf{a}, \mathbf{c})$ and HRTEM $(\mathbf{b}, \mathbf{d})$ images of carbon spheres $(\mathbf{a}, \mathbf{b})$ and carbon-supported metal nickel (c,d).
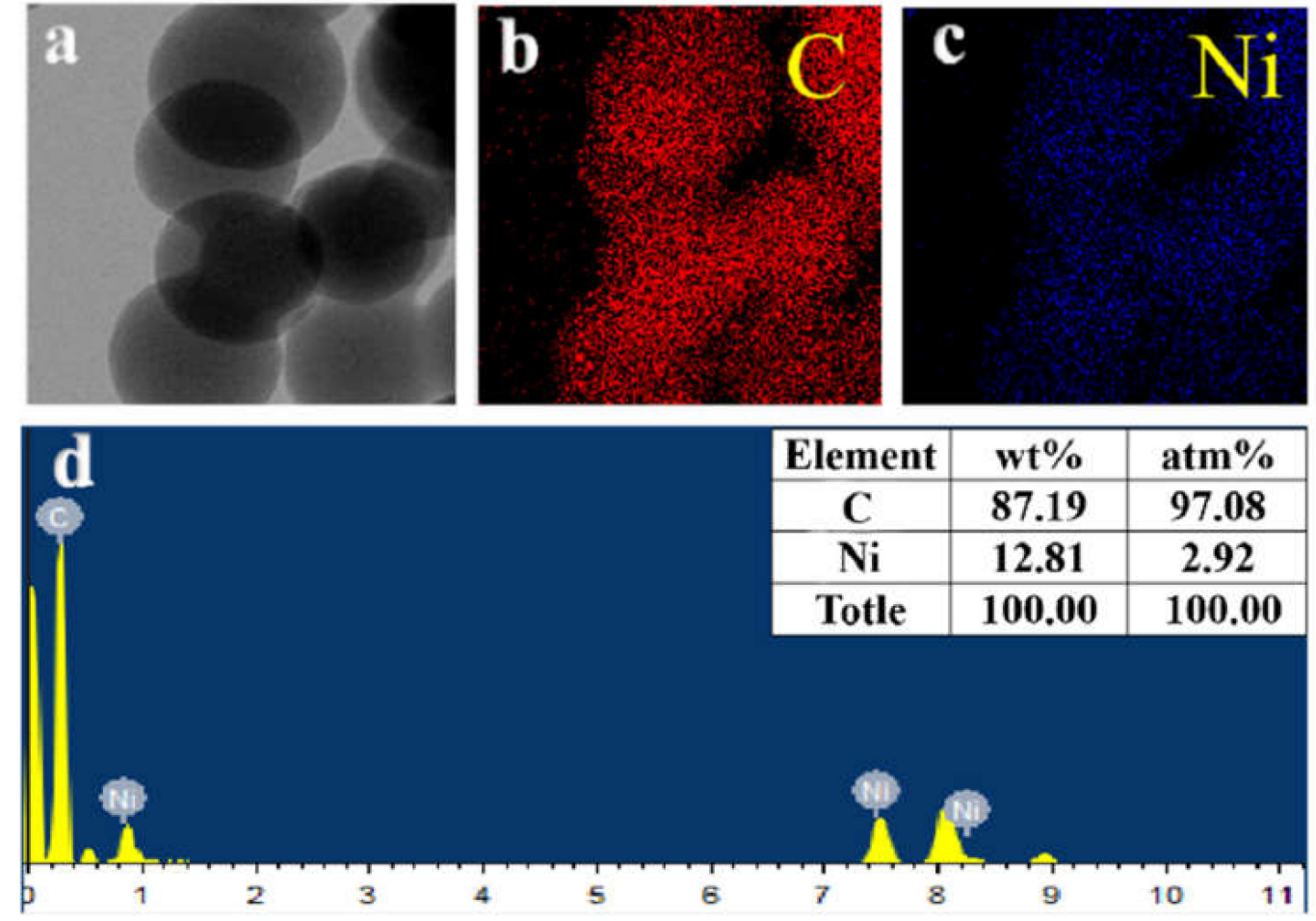

Figure 2. [M7] HRTEM image (a), the corresponding element mapping of C (b) and Ni (c) elements, EDS pattern (d) and elemental contents (inset) of carbon-supported metal Ni. 
Figure 3a shows the XRD pattern of carbon-supported metal nickel, in which the diffraction peaks appear near $44.5^{\circ}, 51.8^{\circ}$, and $76.4^{\circ}$. Compared with the standard pattern of face-centered cubic Ni (JCPDS No. 04-0850) [37], these diffraction peaks correspond to (111), (200), and (220) crystal planes of metal Ni, indicating that metal nickel is face-centered cubic structure. According to the Scherrer formula [36], the average particle size of metal nickel nanocrystals is deduced to be about $2.4 \mathrm{~nm}$, which is in good agreement with the results of HRTEM. Moreover, there is a protrusion between $15-30^{\circ}$, which can be attributed to the presence of amorphous carbon phase $[19,36]$. Compared with the XRD curves of carbon spheres (Figure 4a), this protrusion is attributed to carbon spheres. Due that the carbon spheres are composed of the amorphous carbon, no obvious peak of carbon is found in the XRD curves. In addition, no other diffraction peaks are found in the figure, indicating that the nickel element is completely reduced to metal nickel. This implies that the presence of metal nickel in the carbon-supported metal Ni composite is due to the reducing atmosphere formed in the preparation process. Furthermore, the existence of amorphous carbon in the composite plays a protective role and further prevents the oxidation of metal nickel [37]. The as-prepared carbon-supported metal nickel composite has strong magnetic properties and is helpful for the separation and recovery of adsorbents in water treatment applications [38-40].
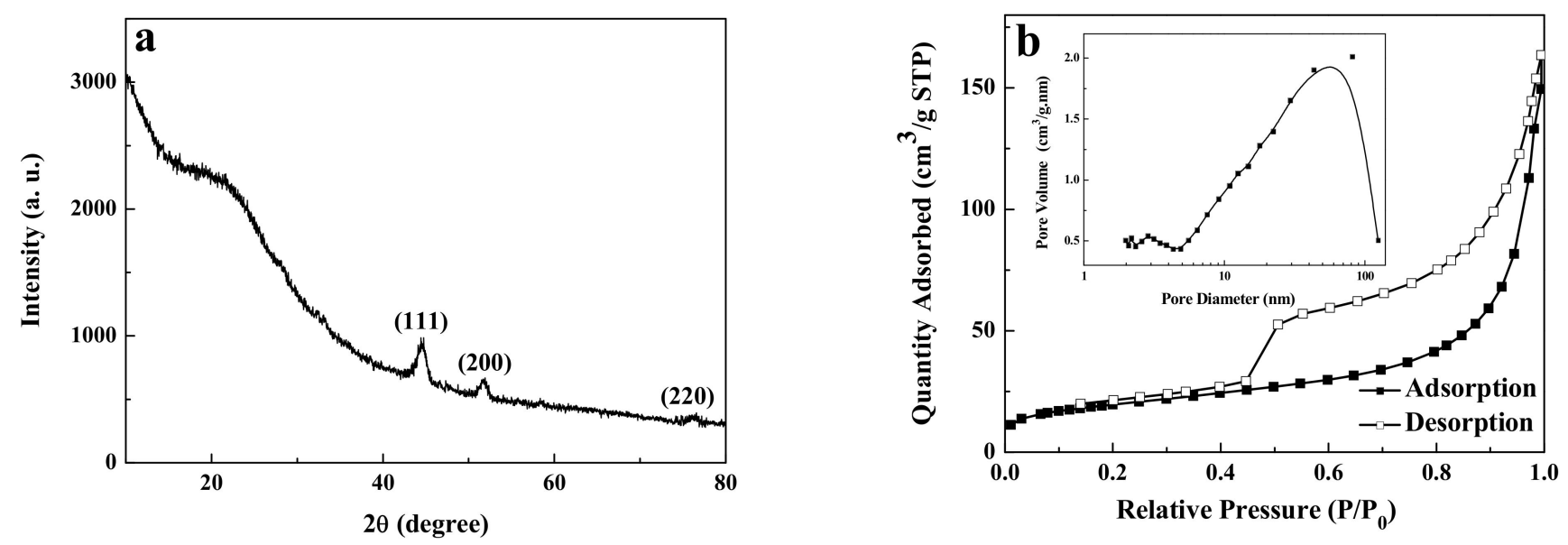

Figure 3. XRD pattern (a), and nitrogen adsorption-desorption isotherm and pore size distribution (inset) of carbon-supported metal nickel (b).
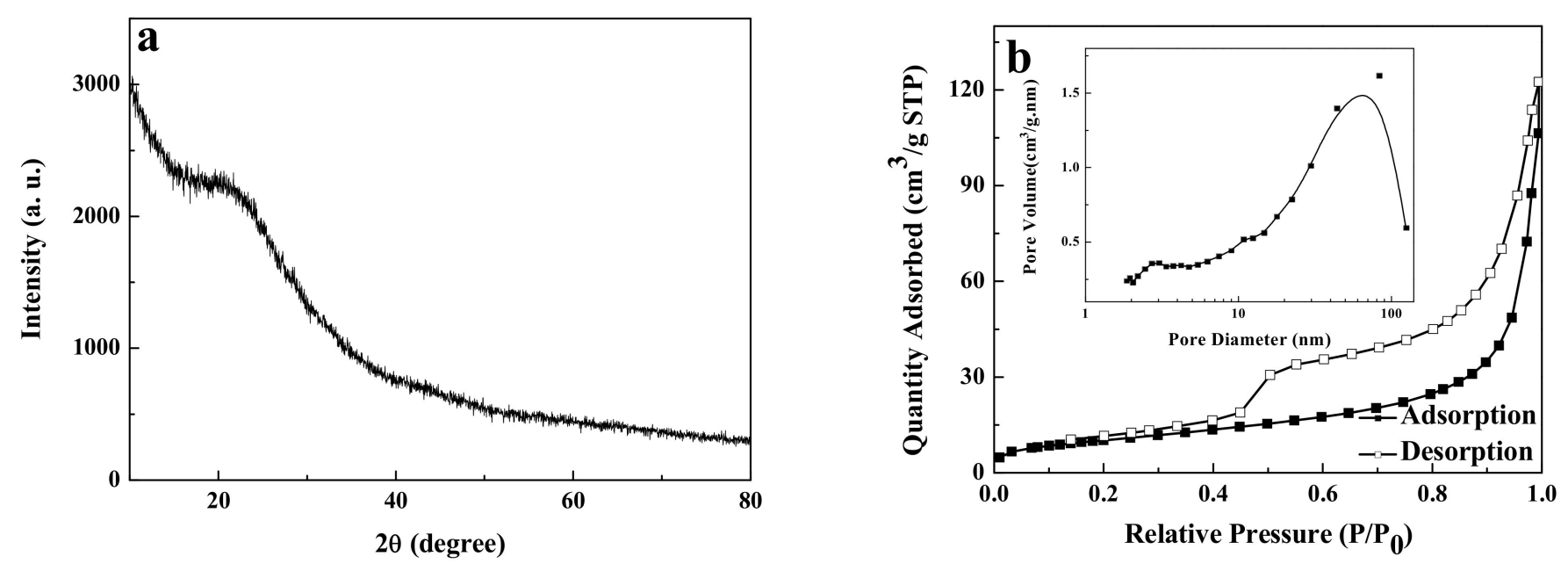

Figure 4. XRD pattern (a), and nitrogen adsorption-desorption isotherm (b) and pore size distribution (inset) of carbon spheres. 
Based on the morphology observation, the porous nature and specific surface area of the samples should be investigated by the $\mathrm{N}_{2}$ adsorption-desorption isotherms and pore size distribution. The carbon-supported metal nickel with $70.35 \mathrm{~m}^{2} \cdot \mathrm{g}^{-1}$ shows a higher specific surface area than the carbon spheres $\left(37.46 \mathrm{~m}^{2} \cdot \mathrm{g}^{-1}\right)$, which may be due to the introduction of metal nickel nanodots with small size. As shown in Figures $3 b$ and $4 b$, both the carbon-supported metal nickel composite and carbon spheres show type IV isotherms and the hysteresis loop at the $P / P_{0}$ value of $0.20-1$, indicating the existence of mesoporous structure $[41,42]$. The porous features from the surface cavities of carbon spheres and the interleaving spheres are further verified by the pore size distribution from the BJH model [43]. For the carbon-supported metal nickel, the pore diameter of the carbon-supported metal nickel is measured to be about $2.82 \mathrm{~nm}$ and $56.24 \mathrm{~nm}$ (inset of Figure $3 \mathrm{~b}$ ). The mesopores smaller than $50 \mathrm{~nm}$ may be produced by the heat treatment, and the large pores may be due to the accumulation of nanospheres [44]. The carbon spheres have the similar $\mathrm{N}_{2}$ adsorption-desorption isotherms to the carbon-supported metal nickel, but have the larger pores at $2.99 \mathrm{~nm}$ and $65.16 \mathrm{~nm}$, leading to the lower specific surface area. Moreover, a large number of independent and complete spheres are produced, which is helpful to improve the specific surface area. The above result is in good agreement with the SEM and HRTEM results.

The magnetic measurement of the carbon-supported metal nickel is shown in Figure 5. There is no obvious hysteresis for the sample, indicating the paramagnetic behavior at room temperature [45]. The saturation magnetization is measured to be $72.68 \mathrm{emu} \cdot \mathrm{g}^{-1}$, which can ensure the separation and recovery of the adsorbent in practical application [46]. Compared with the traditional filtration and centrifugation, the magnetic carbon-supported metal nickel is easily separated and recovered by applying an external magnetic field, exhibiting promising potential in large scale industrial applications.

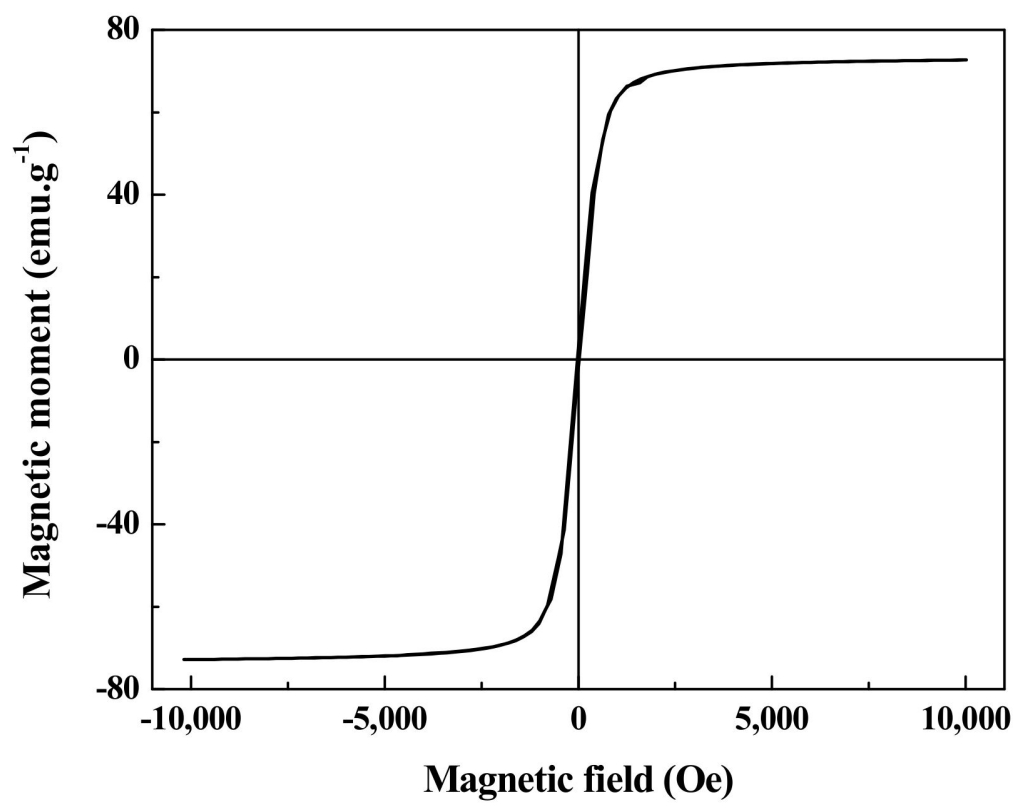

Figure 5. The magnetic hysteresis loops of the carbon-supported metal nickel.

\subsection{Adsorption Performance}

\subsubsection{Effect of $\mathrm{pH}$ Value}

The $\mathrm{pH}$ value plays an important role in investigating the adsorption performance of the carbon-supported metal nickel composite [45]. The reactive brilliant yellow R-4GLN solution with an initial concentration of $25 \mathrm{mg} / \mathrm{L}$ was prepared with distilled water. The $\mathrm{pH}$ values of the initial solution were adjusted to $1,1.45,1.62,2,3,4,5,6,7$, and 8 by concentrated hydrochloric acid, $0.1 \mathrm{~mol} / \mathrm{L}$ of hydrochloric acid, or $0.1 \mathrm{~mol} / \mathrm{L}$ of $\mathrm{NaOH}$ solution, and oscillated for $2.5 \mathrm{~h}$ at a constant temperature of $308 \mathrm{~K}$. 
Figure 6 shows the effect of $\mathrm{pH}$ value on the removal efficiency of reactive brilliant yellow R-4GLN solution over carbon-supported metal nickel composite. It can be seen from the figure that the $\mathrm{pH}$ value of the solution has a significant effect on adsorption performance. The lower the $\mathrm{pH}$ value, the better the adsorption performance. When $\mathrm{pH}$ value is lower than 2 , the removal efficiency is close to $100 \%$. With the increasing $\mathrm{pH}$ value, the removal efficiency first decreases and then increases. When $\mathrm{pH}=5$, the removal efficiency is $45.26 \%$, which reaches the lowest value. Then, as the $\mathrm{pH}$ value increases, the removal efficiency increases slightly, but it does not exceed $75 \%$. In an acidic environment, the composite is protonated and the surface of the adsorbent is positively charged, leading to the maximum adsorption of anionic dyes $[47,48]$. So, the decrease of $\mathrm{pH}$ value means the enlarged positive potential of the composite, which results in the increasing adsorption capacity for anionic dye $[47,48]$. In summary, the adsorbent has a better adsorption effect when the $\mathrm{pH}$ value is small. When $\mathrm{pH}=1.62$, it reaches adsorption saturation. Considering the adsorption performance and economic cost, the $\mathrm{pH}$ value of the solution was set at 1.62 in this experiment.

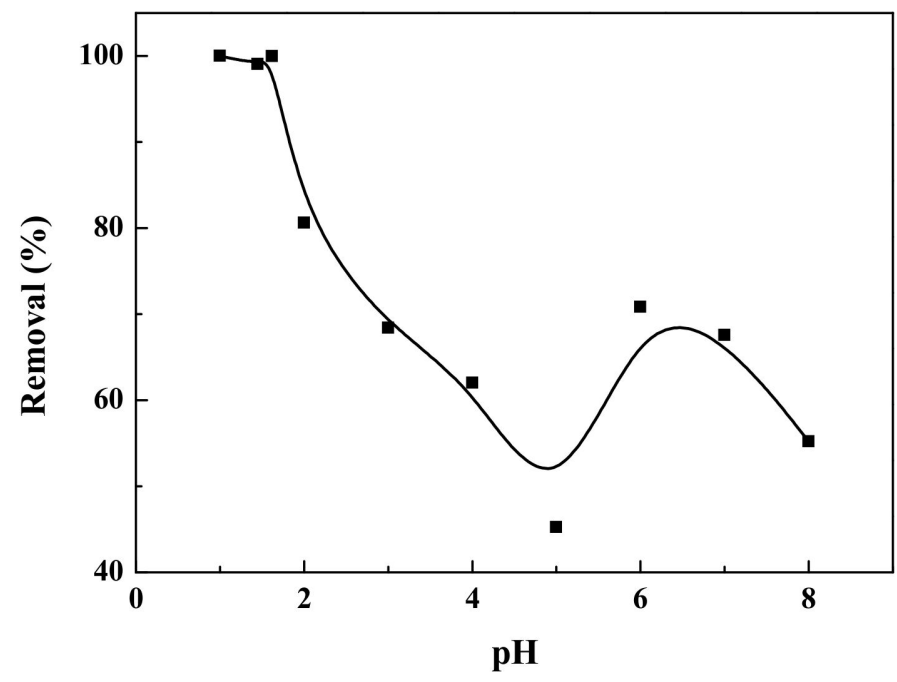

Figure 6. The adsorption effect of carbon-supported metal nickel on reactive brilliant yellow R-4GLN under different $\mathrm{pH}$ values.

\subsubsection{Effect of Contact Time}

The adsorption performance was influenced by variable contact times. As shown in Figure 7, at the beginning of adsorption, the initial rate of adsorption removal increases rapidly with the extension of contact time. For carbon-supported metal nickel, more than $95 \%$ of reactive brilliant yellow $\mathrm{R}-4 \mathrm{GLN}$ is removed within the contact time of $5 \mathrm{~min}$, and nearly $100 \%$ is removed within the contact time of $20 \mathrm{~min}$, displaying the quick and effective adsorption. However, for carbon spheres, only 35\% of reactive brilliant yellow R-4GLN is removed under the adsorption for $40 \mathrm{~min}$. When the adsorption reaches equilibrium, only $38 \%$ is removed. This is proved by the adsorption capacity curve at Figure 7 . Therefore, compared with carbon spheres, the carbon-supported metal nickel exhibits the efficient and rapid adsorption, which reveals that a quick monolayer formation occurred on the external surface of the composite [48]. And the excellent adsorption performance for the magnetic composite may be due to the large specific surface area caused by the unique morphology and structure. 


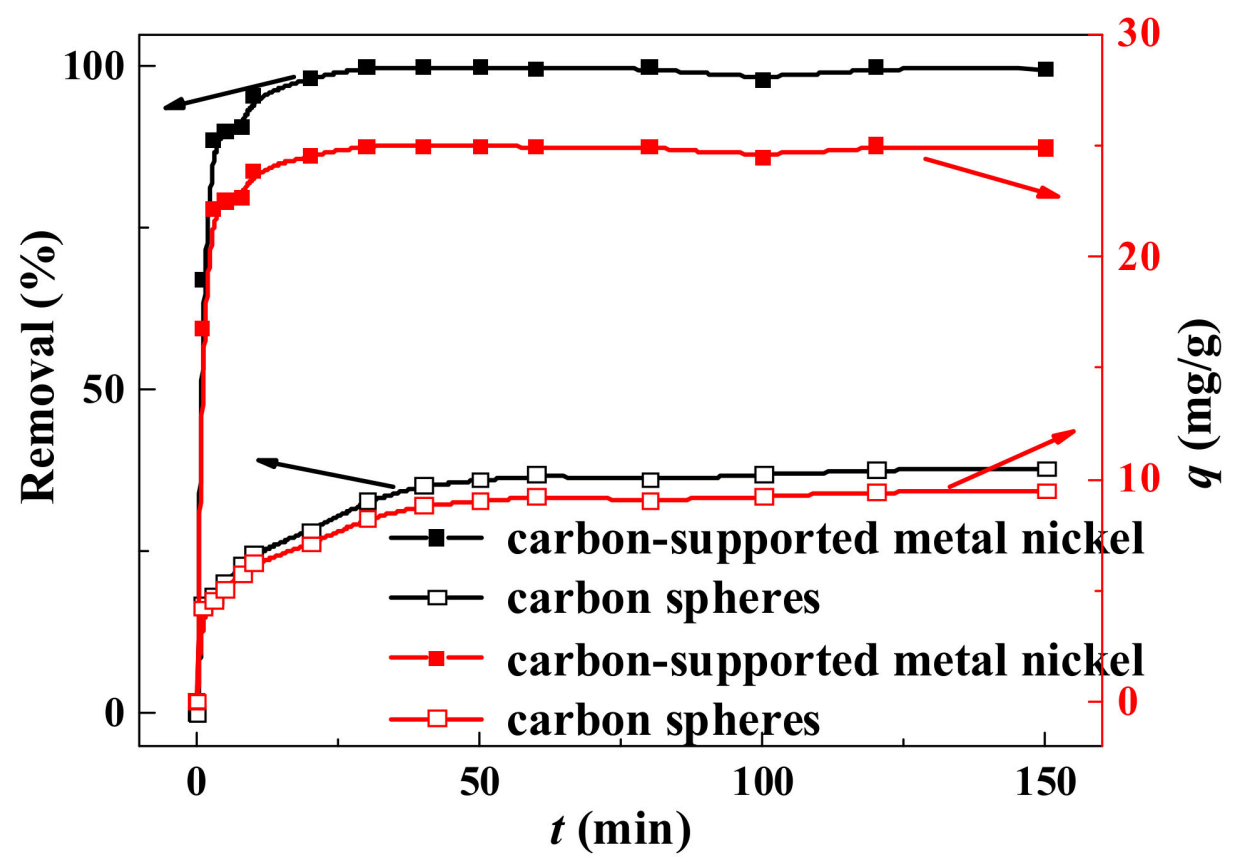

Figure 7. Effect of contact time on the removal of reactive brilliant yellow R-4GLN over carbon spheres and carbon-supported metal nickel.

\subsubsection{Effect of Initial Dye Concentration}

The effect of initial dye concentration on the adsorption performance was investigated in a range from 1 to $325 \mathrm{mg} / \mathrm{L}$. To ensure the accuracy of initial dye concentration, $1 \mathrm{~g} / \mathrm{L}$ of reactive brilliant yellow R-4GLN solution was prepared with distilled water, and then diluted to different concentrations. The $\mathrm{pH}$ value of the solution was adjusted to 1.62 with concentrated hydrochloric acid and oscillated at a constant temperature of $308 \mathrm{~K}$ for $5 \mathrm{~h}$. Figure 8a shows the effect of the initial concentration of the dye solution on adsorption performance. It can be seen from the figure that the dye removal displayed a change trend of rapid increase at first and then gradually becoming stable with the increase of the initial concentration. At the low concentration, the dye molecules are easily adsorbed on the available surface of the adsorbent [48]. However, at high dye concentration, the surface active sites of the adsorbent are saturated, which causes the adsorption to become slow [48]. When the initial concentration is $290 \mathrm{mg} / \mathrm{L}$, the adsorption capacity at equilibrium is $207.78 \mathrm{mg} / \mathrm{g}$.
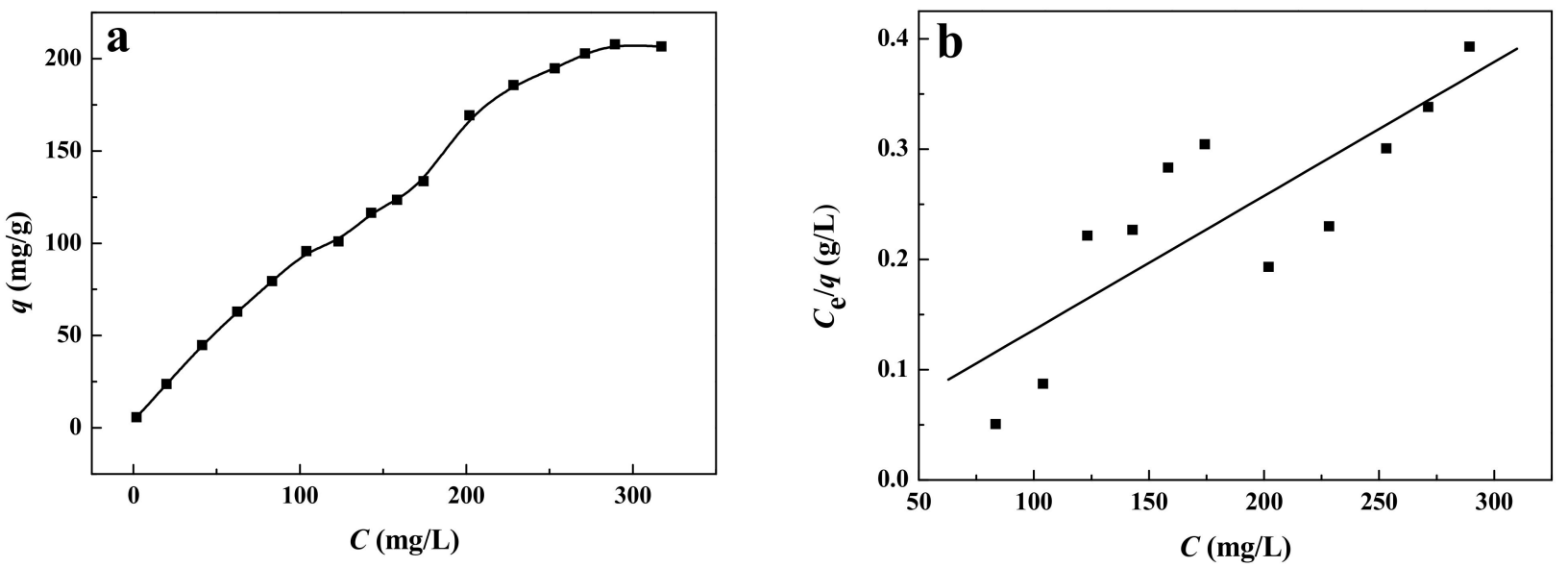

Figure 8. (a) Effect of the initial dye concentration on adsorption performance and (b) $C_{\mathrm{e}} / q$ - $C$ curve. 
The adsorption properties of the as-prepared magnetic carbon-supported metal Ni were compared with previously reported adsorbents in Table 1. Various carbon-based adsorbents can effectively remove the organic pollutions from wastewater under their own experimental conditions. Compared with other carbon-based adsorbents, the as-prepared magnetic carbon-supported metal Ni composite exhibits the good adsorption property with the adsorption capacities of $207.78 \mathrm{mg} / \mathrm{g}$ for reactive brilliant yellow R-4GLN.

Table 1. Carbon-based adsorbents for the removal of organic pollutions.

\begin{tabular}{|c|c|c|c|}
\hline Carbon-Based Adsorbents & Organic Pollutions & $q_{\mathrm{m}}(\mathrm{mg} / \mathrm{g})$ & Reference \\
\hline \multirow[t]{2}{*}{ Magnetic carbon-supported metal Ni } & Reactive brilliant yellow R-4GLN & 207.78 & This work \\
\hline & Methyl blue & $97.85 \pm 18.14$ & \\
\hline \multirow[t]{3}{*}{ Magnetite/carbon adsorbents from apple } & Congo red & $500.55 \pm 174.96$ & [49] \\
\hline & Rhodamine B & $254.77 \pm 144.84$ & \\
\hline & Methyl blue & $135.72 \pm 13.34$ & \\
\hline \multirow[t]{3}{*}{ Magnetite/carbon adsorbents from banana } & Congo red & $433.83 \pm 297.38$ & [49] \\
\hline & Rhodamine B & $270.71 \pm 83.26$ & \\
\hline & Methyl blue & $183.05 \pm 58.51$ & \\
\hline \multirow[t]{2}{*}{ Magnetite/carbon adsorbents from orange peels } & Congo red & $337.98 \pm 94.61$ & [49] \\
\hline & Rhodamine B & $196.14 \pm 53.51$ & \\
\hline Layered double hydroxide-carbon dot composite & Methyl blue & 185 & [50] \\
\hline \multirow[t]{2}{*}{ Activated carbon based on synthetic and agricultural wastes } & Methyl orange & 38.83 & [51] \\
\hline & Methylene blue & $\sim 148$ & \\
\hline \multirow[t]{2}{*}{ Carboxylic acid-terminated carbon nanoflakes } & Crystal violet & $\sim 132$ & [52] \\
\hline & Rhodamine B & $\sim 118$ & \\
\hline Activated carbon-based multicarboxyl adsorbent & Rhodamine $6 \mathrm{G}$ & 122.55 & [53] \\
\hline \multirow{2}{*}{$\begin{array}{c}\text { Carbon nanotube incorporated eucalyptus derived } \\
\text { activated carbon-based adsorbent }\end{array}$} & Methylene blue & 49.61 & \\
\hline & Eosin yellow & 49.15 & [54] \\
\hline \multirow{2}{*}{ Sugarcane bagasse carbon-based composite } & Methylene blue & 261 & {$[55]$} \\
\hline & Methyl violet & 125 & [5b] \\
\hline Candle soot coated polyurethane foam & Rhodamine B & 15.066 & [56] \\
\hline
\end{tabular}

In order to achieve the effective and rapid adsorption, investigation of the adsorption kinetics is very necessary and important. The Langmuir model is fitted according to the adsorption isotherm, and the adsorption isotherm can be obtained from Figure $8 \mathrm{~b}$ by the equation $C_{\mathrm{e}} / q=0.0012 C_{\mathrm{e}}+0.0146\left(R_{2}=0.682\right)$, where $C_{\mathrm{e}}$ is the concentration of dye solution at equilibrium. From this equation we can calculate $q_{e}=833 \mathrm{mg} / \mathrm{g}, K_{\mathrm{L}}=0.0822 \mathrm{~L} / \mathrm{mg}$, where $q_{\mathrm{e}}$ is the quantity of dye per mass of adsorbate at equilibrium $(\mathrm{mg} / \mathrm{g})$ and $K_{\mathrm{L}}$ $(\mathrm{L} / \mathrm{mg})$ is the Langmuir constant [48]. The basic characteristics of Langmuir model can be described by the infinite dispersion constant $\left(R_{\mathrm{L}}=\left(1+K C_{0}\right)^{-1}\right)$ [57], where $R_{\mathrm{L}}$ is also known as equilibrium parameter, $C_{0}$ is the initial concentration $(\mathrm{mg} / \mathrm{L})$, and $K$ is the Langmuir constant related to the energy of adsorption $(\mathrm{L} / \mathrm{mg})$ [48]. The reliability of Langmuir equation is determined according to $R_{\mathrm{L}}$ value. When $0<R_{\mathrm{L}}<1$, it indicates that the obtained data basically conforms to Langmuir model. When $R_{\mathrm{L}}=1$, the obtained data conforms to Langmuir model, and the obtained Langmuir equation is reliable. When $R_{\mathrm{L}}=0$ or $R_{\mathrm{L}}>1$, it shows that the obtained data do not conform to Langmuir model, and the obtained Langmuir equation is not reliable [58]. According to the calculated $R_{\mathrm{L}}$ data as shown in Table 2, the experimental data basically conforms to Langmuir model.

Table 2. Effect of the initial dye concentration $C_{0}$ on the infinite dispersion constant $R_{\mathrm{L}}$.

\begin{tabular}{ccccccccccccccccccccc}
\hline $\begin{array}{c}\mathrm{C}_{0} \\
\left(\mathrm{mg} \cdot \mathrm{L}^{-1}\right)\end{array}$ & 2 & 20 & 41 & 62 & 83 & 104 & 123 & 143 & 158 & 174 & 202 & 228 & 253 & 271 & 289 & 317 \\
\hline$R_{\mathrm{L}}$ & 0.87 & 0.38 & 0.23 & 0.16 & 0.13 & 0.10 & 0.09 & 0.08 & 0.07 & 0.07 & 0.06 & 0.05 & 0.05 & 0.04 & 0.04 & 0.04 \\
\hline
\end{tabular}

\subsubsection{Effect of Adsorption Temperature}

Figure 9a displays the effect of the adsorption temperature on the removal of the reactive brilliant yellow R-4GLN solution with an initial concentration of about $25 \mathrm{mg} / \mathrm{L}$ at the $\mathrm{pH}$ value of 1.62. It can be seen from Figure $9 \mathrm{a}$ that the removal efficiency of the 
reactive brilliant yellow R-4GLN over carbon-supported metal nickel increases with the increasing adsorption temperature. This may be attributed to the enhanced mobility of dye that is provided by the sufficient energy to interact with the available active sites of adsorbent molecule [48]. Therefore, the adsorption properties are enhanced at the higher temperature. By the $\ln \left(q / C_{\mathrm{e}}\right) \sim 1 / T$ curve in Figure $9 \mathrm{~b}$, the fitting equation can be obtained as follows.

$$
y=-2297.2 x+7.51(R 2=0.9861)
$$
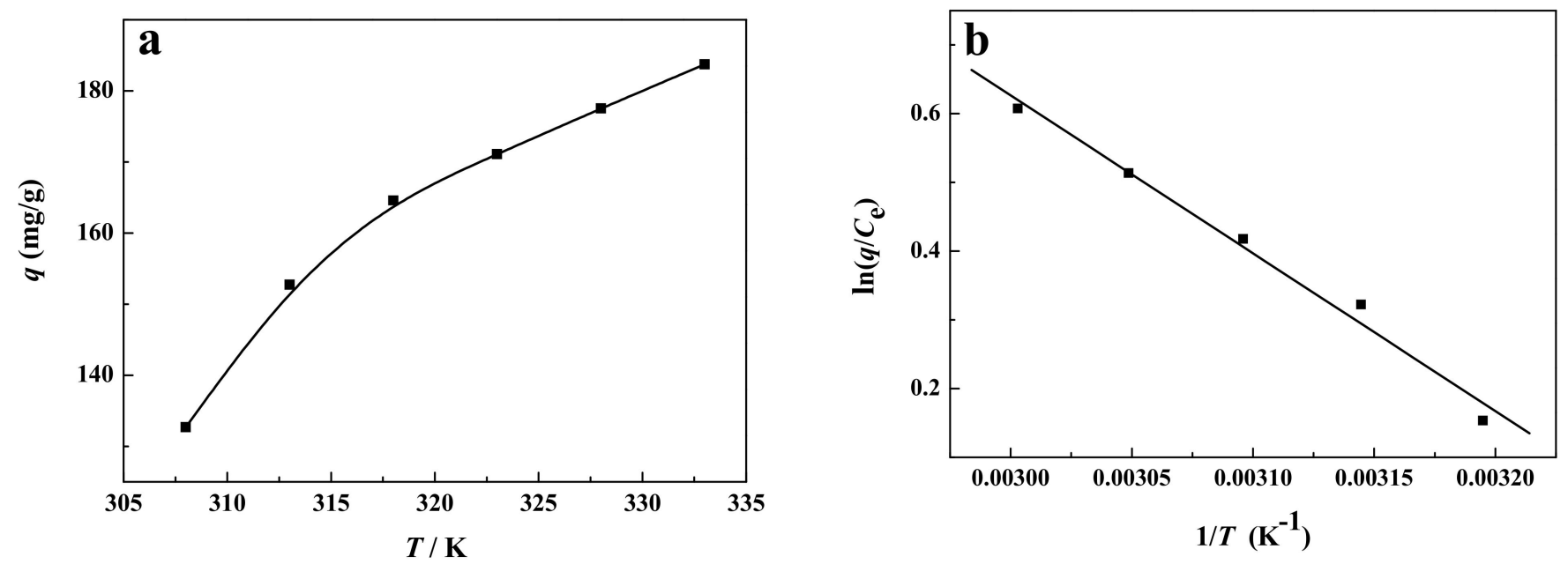

Figure 9. (a) Effect of adsorption temperature on removal of dye and $(\mathbf{b}) \ln \left(q / C_{e}\right)-1 / T$ curve.

According to the line slope $-\Delta H / R$, the enthalpy changes $\Delta H=19.098 \mathrm{~kJ} / \mathrm{mol}$ in the range of 308-333 $\mathrm{K}$ can be calculated, indicating that the adsorption process is an endothermic process. Therefore, the increase of the temperature is very beneficial to the adsorption. Due to the enthalpy change value at the range of $0.418 \sim 62.7 \mathrm{~kJ} / \mathrm{mol}$, the adsorption performance of carbon-supported metal nickel on reactive brilliant yellow R-4GLN can be interpreted mainly by physical adsorption. On the other hand, higher temperature can enhance the desorption of dye due to violent molecular motion, leading to the decrease of adsorption capacity. Thus, the temperature is kept at $308 \mathrm{~K}$.

\subsubsection{Effect of Adsorbent Dosage}

The effect of adsorbent mass is usually used to investigate the solid adsorbent's capacity at a given initial concentration of adsorbate in a solution. Figure 10 shows the effect of the amount of adsorbent on the removal of reactive brilliant yellow R-4GLN solution with $25 \mathrm{mg} / \mathrm{L}$ and $\mathrm{pH}=1.62$. It can be seen from the figure that when the amount of adsorbent is less than $8 \mathrm{mg}$, the removal efficiency increases with the increasing amount of adsorbent. When the amount is $1 \mathrm{mg}$, only $36.97 \%$ of dye is removed. With the adsorbent amount of $4 \mathrm{mg}$, about $82.30 \%$ of dye can be removed. And when the amount is more than $6 \mathrm{mg}$, the removal of dye is close to $100 \%$. This phenomenon occurs mainly because with the increase of adsorbent mass, the amount of adsorbed active brilliant yellow R-4GLN increases accordingly. The amount of adsorbent dosage plays a crucial role in the dye removal process [48]. 


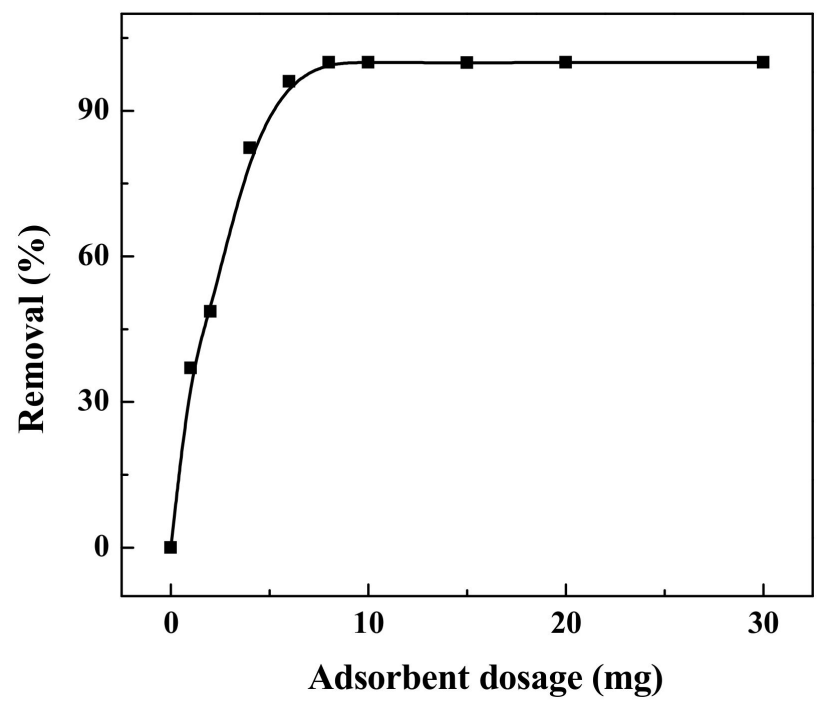

Figure 10. Effect of the adsorbent dosage on the adsorption performance.

\subsubsection{Universality of Adsorbent}

To investigate the universality of carbon-supported metal nickel composite, various dyes like reactive violet $X-2 R$, reactive turquoise blue BF-BGN, reactive golden yellow B-4RFN, reactive dark blue B-2GW, reactive black P-BR and reactive red R-4BD with an initial concentration of about $25 \mathrm{mg} / \mathrm{L}$ were removed at a constant temperature of $308 \mathrm{~K}$. UV-visible analysis of each dye solution before and after adsorption was carried out in the same way to calculate the removal efficiency of various dyes.

It can be seen from Figure 11 that carbon-supported metal nickel exhibits the good adsorption performance on various dyes, and the relative data are shown in Table 3 . When $\mathrm{pH}=1.62$, the removal efficiency of the reactive violet $\mathrm{X}-2 \mathrm{R}$ solution, reactive turquoise blue BF-BGN solution, reactive golden yellow B-4RFN solution, and reactive red R-4BD solution can reach more than $95 \%$, and that of reactive black P-BR solution can reach $89 \%$, and that of reactive dark blue B-2GW solution is also $83 \%$. Under neutral condition, the removal efficiency of reactive turquoise blue BF-BGN solution can also reach $80 \%$, while that of other dyes is relatively low. It can be seen that carbon-supported metal nickel has universal applicability for the adsorption of various reactive dyes, and the adsorption performance under acidic conditions is better than that under neutral condition. The research results show that carbon-supported metal nickel has potential application value in wastewater treatment.

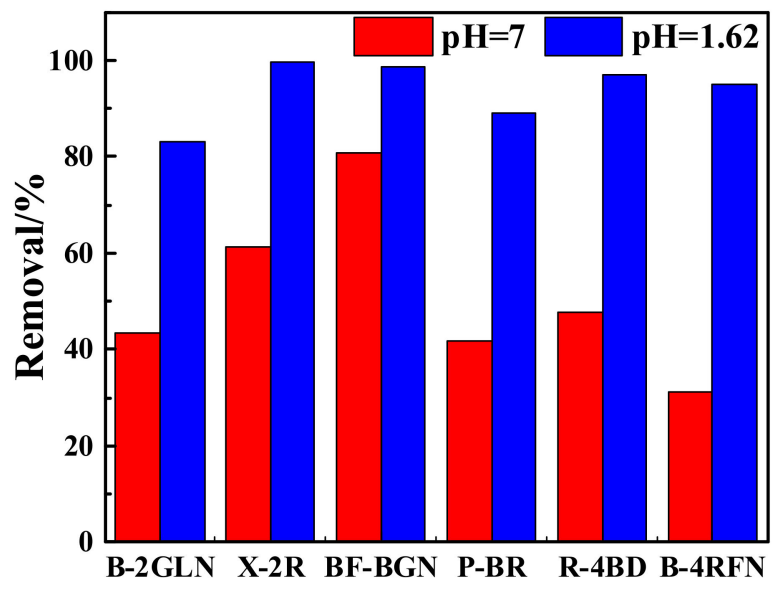

Figure 11. The adsorption performance of carbon-supported metal nickel on various dyes under neutral conditions and $\mathrm{pH}=1.62$. 
Table 3. Removal efficiency of various dyes over carbon-supported metal nickel at $\mathrm{pH}=7$ and $\mathrm{pH}=1.62$.

\begin{tabular}{ccccccc}
\hline Condition & $\begin{array}{c}\text { Reactive Dark } \\
\text { Blue B-2GLN }\end{array}$ & $\begin{array}{c}\text { Reactive Violet } \\
\text { X-2R }\end{array}$ & $\begin{array}{c}\text { Reactive } \\
\text { Turquoise Blue } \\
\text { BF-BGN }\end{array}$ & $\begin{array}{c}\text { Reactive Black } \\
\text { P-BR }\end{array}$ & $\begin{array}{c}\text { Reactive Red } \\
\text { R-4BD }\end{array}$ & $\begin{array}{c}\text { Reactive } \\
\text { Golden Yellow } \\
\text { B-4RFN }\end{array}$ \\
\hline $\begin{array}{c}\text { Removal } \\
\text { efficiency at } \\
\text { pH = }(\%) \\
\begin{array}{c}\text { Removal } \\
\text { efficiency at }\end{array}\end{array}$ & 43.37 & 61.46 & 80.72 & 41.85 & 47.79 \\
pH $=1.62(\%)$ & 83.15 & 99.83 & 98.82 & 89.19 & 96.95 \\
\hline
\end{tabular}

\subsubsection{Cyclic Stability}

To evaluate the reproducibility and stability of the carbon-supported metal nickel, the adsorption test of 20 times were carried out in Figure 12. It is found that after 20 cycles, the removal efficiency of reactive brilliant yellow R-4GLN solution is still close to $100 \%$, indicating the good stability of carbon-supported metal nickel. Based on the XRD and HRTEM images of the carbon-supported metal nickel after 20 cycles (Figure 13), it is found that the used carbon-supported metal nickel remains the similar crystal structure and morphology to the unused sample. Moreover, the average particle size of metal nickel nanocrystals is about $2.5 \mathrm{~nm}$ and the content of metal nickel in the used composite is about $12.62 \mathrm{wt} \%$, in good agreement with the fresh sample, indicating the good stability and reusability.

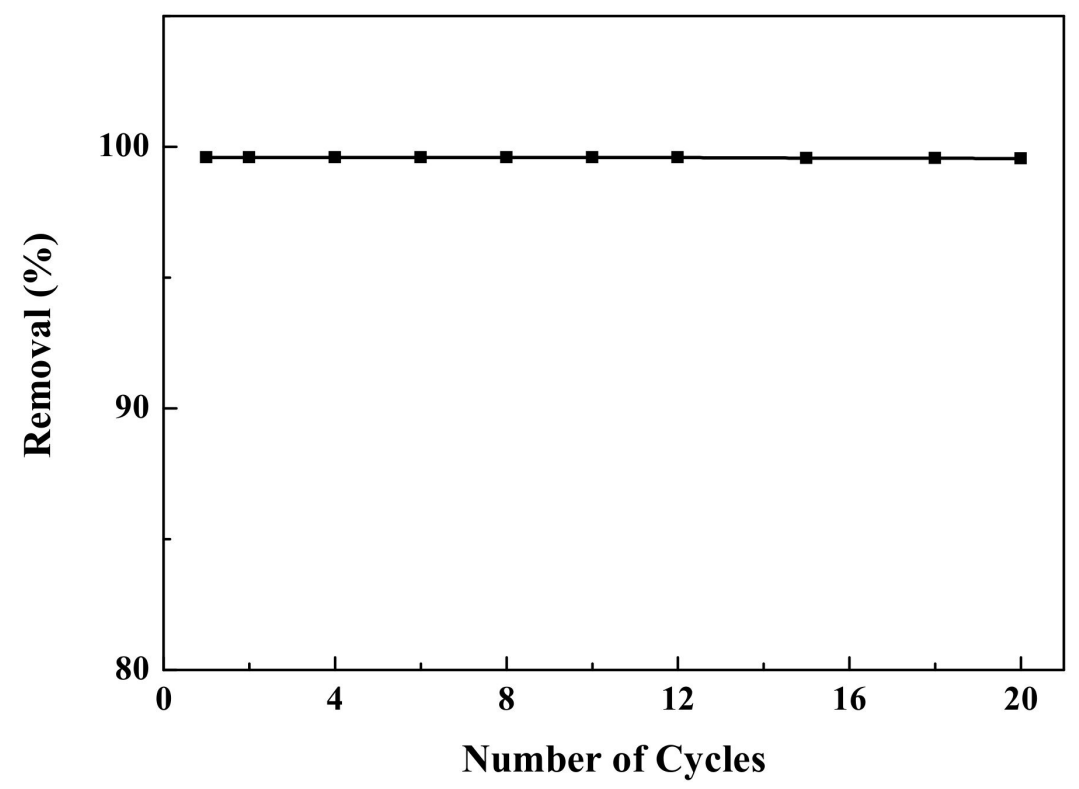

Figure 12. Effect of number of cycles on the removal efficiency of reactive brilliant yellow R-4GLN solution over carbon-supported metal nickel. 

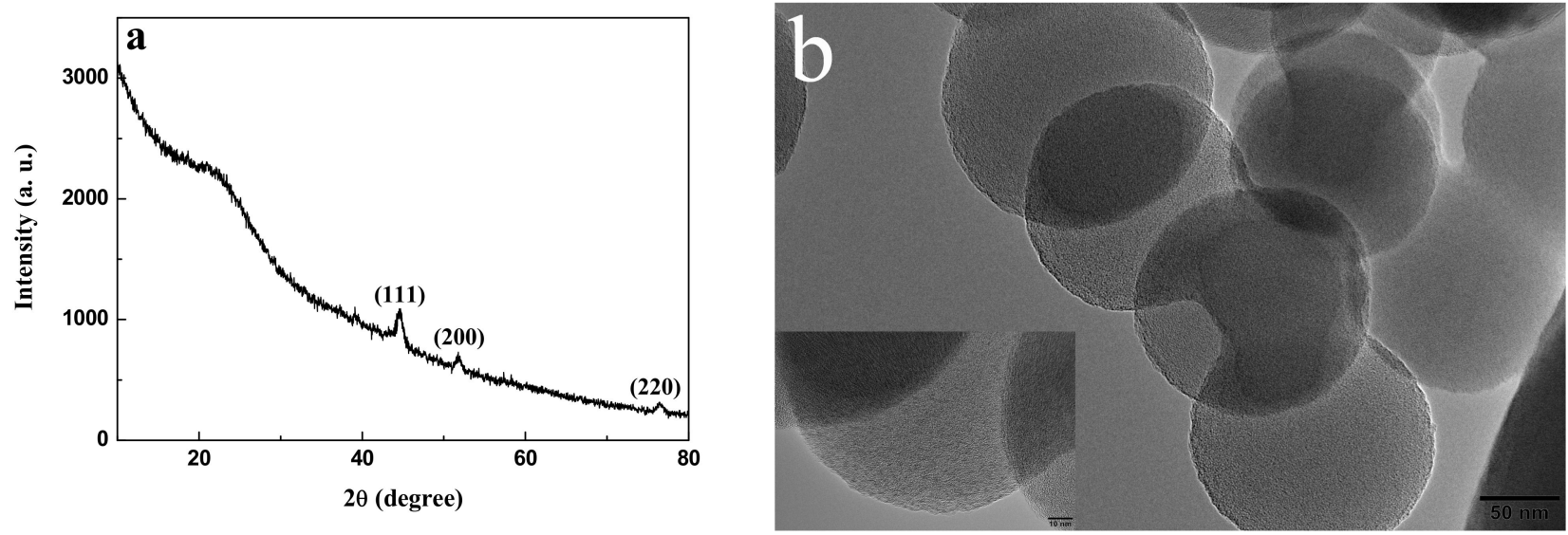

Figure 13. XRD pattern (a) and HTEM image (b) of the used carbon-supported metal nickel after 20 cycles. The inserted figure in (b) is a partially enlarged view of the sample.

\section{Conclusions}

In this paper, the carbon-supported metal nickel magnetic nanomaterials were synthesized on a large scale, and the adsorption performance on various reactive dyes has been studied. The preparation is simple and easy to operate. The magnetic adsorbent is easy to be separated and recovered from the solution under an external magnetic field. Compared with carbon spheres, the carbon-supported metal nickel displays good adsorption performance for various reactive dyes in wastewater. When $\mathrm{pH}=1.62$, the removal efficiency is close to $100 \%$, and the adsorption rapidly reaches saturation within $5 \mathrm{~min}$. In the $\mathrm{pH}$ range of $2-8$, as the $\mathrm{pH}$ value increases, the removal efficiency decreases slightly, and both exceeds $45 \%$, indicating that carbon-supported metal nickel can be used as adsorbent in a variety of different $\mathrm{pH}$ systems. The adsorption performance of carbon-supported metal nickel nanomaterials conforms to Langmuir model with good universality. In this paper, a carbonbased adsorbent with a simple synthesis method and low cost was constructed, and its high adsorption performance indicates its potential application in dye wastewater treatment.

Author Contributions: Conceptualization, F.T.; Formal analysis, J.X.; Investigation, B.L. and P.L.; Writing-original draft, B.L. and H.K.; Writing-review and editing, W.W. All authors have read and agreed to the published version of the manuscript.

Funding: This research was funded by the National Natural Science Foundation of China, grant number 41772311 and 52179107.

Institutional Review Board Statement: Not applicable.

Informed Consent Statement: Not applicable.

Data Availability Statement: The data presented in this study are available on request from the corresponding author.

Acknowledgments: Authors thank Ru Huang from the School of Chemistry and Chemical Engineering, Shaoxing University, for the help in the process of micro testing.

Conflicts of Interest: The authors declare no conflict of interest.

\section{References}

1. Li, X.; Xiong, S.; Li, J.; Bai, J.; Qian, Y. Mesoporous NiO ultrathin nanowire networks topotactically transformed from $\alpha-\mathrm{Ni}(\mathrm{OH})_{2}$ hierarchical microspheres and their superior electrochemical capacitance properties and excellent capability for water treatment. J. Mater. Chem. 2012, 22, 14276-14283. [CrossRef]

2. Caudo, S.; Genovese, C.; Perathoner, S.; Centi, G. Copper-pillared clays (Cu-PILC) for agro-food wastewater purification with $\mathrm{H}_{2} \mathrm{O}_{2}$. Microporous Mesoporous Mater. 2008, 107, 46-57. [CrossRef]

3. Eltaweil, A.S.; Elshishini, H.M.; Ghatass, Z.F.; Elsubruiti, G.M. Ultra-high adsorption capacity and selective removal of Congo red over aminated graphene oxide modified Mn-doped UiO-66 MOF. Powder Technol. 2021, 379, 407-416. [CrossRef] 
4. Zeng, Q.; Liu, Y.; Shen, L.; Lin, H.; Yu, W.; Xu, Y.; Li, R.; Huang, L. Facile preparation of recyclable magnetic Ni@filter paper composite materials for efficient photocatalytic degradation of methyl orange. J. Colloid Interf. Sci. 2020, 582, 291-300. [CrossRef] [PubMed]

5. Usman, M.; Ahmed, A.; Yu, B.; Wang, S.; Shen, Y.; Cong, H. Simultaneous adsorption of heavy metals and organic dyes by beta-Cyclodextrin-Chitosan based cross-linked adsorbent. Carbohyd Polym. 2021, 255, 117486. [CrossRef]

6. Liu, C.-H.; Wu, J.-S.; Chiu, H.-C.; Suen, S.-Y.; Chu, K.H. Removal of anionic reactive dyes from water using anion exchange membranes as adsorbers. Water Res. 2007, 41, 1491-1500. [CrossRef]

7. Selcuk, H. Decolorization and detoxification of textile wastewater by ozonation and coagulation processes. Dye. Pigment. 2005, 64, 217-222. [CrossRef]

8. Kong, Y.; Zhuang, Y.; Shi, B. Tetracycline removal by double-metal-crosslinked alginate/graphene hydrogels through an enhanced Fenton reaction. J. Hazard. Mater. 2020, 382, 121060. [CrossRef]

9. Okesola, B.O.; Smith, D.K. Applying low-molecular weight supramolecular gelators in an environmental setting-Self-assembled gels as smart materials for pollutant removal. Chem. Soc. Rev. 2016, 45, 4226-4251. [CrossRef]

10. Tavangar, T.; Karimi, M.; Rezakazemi, M.; Reddy, K.R.; Aminabhavi, T.M. Textile waste, dyes/inorganic salts separation of cerium oxide-loaded loose nanofiltration polyethersulfone membranes. Chem. Eng. J. 2020, 385, 123787. [CrossRef]

11. Fattahimoghaddam, H.; Mahvelati-Shamsabadi, T.; Lee, B.-K. Efficient Photodegradation of Rhodamine B and Tetracycline over Robust and Green g-C3N4 Nanostructures: Supramolecular Design. J. Hazard. Mater. 2021, 403, 123703. [CrossRef] [PubMed]

12. Saghir, S.; Xiao, Z. Hierarchical mesoporous ZIF-67@LDH for efficient adsorption of aqueous Methyl Orange and Alizarine Red S. Powder Technol. 2021, 377, 453-463. [CrossRef]

13. Pap, S.; Kirk, C.; Bremner, B.; Sekulic, M.T.; Shearer, L.; Gibb, S.W.; Taggart, M.A. Low-cost chitosan-calcite adsorbent development for potential phosphate removal and recovery from wastewater effluent. Water Res. 2020, 173, 115573. [CrossRef] [PubMed]

14. Litefti, K.; Freire, M.S.; Stitou, M.; González-Álvarez, J. Adsorption of an anionic dye (Congo red) from aqueous solutions by pine bark. Sci. Rep. 2019, 9, 16530. [CrossRef]

15. Yadav, S.; Asthana, A.; Singh, A.K.; Chakraborty, R.; Vidya, S.S.; Susan, A.B.H.; Carabineiro, S.A. Adsorption of cationic dyes, drugs and metal from aqueous solutions using a polymer composite of magnetic/ $\beta$-cyclodextrin/activated charcoal/Na alginate: Isotherm, kinetics and regeneration studies. J. Hazard. Mater. 2021, 409, 124840. [CrossRef]

16. Robati, D.; Mirza, B.; Rajabi, M.; Moradi, O.; Tyagi, I.; Agarwal, S.; Gupta, V.K. Removal of hazardous dyes-BR 12 and methyl orange using graphene oxide as an adsorbent from aqueous phase. Chem. Eng. J. 2016, 284, 687-697. [CrossRef]

17. Yang, X.; Wan, Y.; Zheng, Y.; He, F.; Yu, Z.; Huang, J.; Wang, H.; Ok, Y.S.; Jiang, Y.; Gao, B. Surface functional groups of carbon-based adsorbents and their roles in the removal of heavy metals from aqueous solutions: A critical review. Chem. Eng. J. 2019, 366, 608-621. [CrossRef]

18. Liu, D.; Gu, W.; Zhou, L.; Wang, L.; Zhang, J.; Liu, Y.; Lei, J. Recent advances in MOF-derived carbon-based nanomaterials for environmental applications in adsorption and catalytic degradation. Chem. Eng. J. 2021, 427, 131503. [CrossRef]

19. Ma, J.; Fan, C.; Zuo-Jiang, S.; Wang, Y.; Guan, W.; Ren, W.; Zhang, H.; Wang, S.; Chen, K. Hierarchically Designed Nickel-Entangled Carbon Sphere with Superior Adsorption Properties. Chemistryselect 2018, 3, 2888-2893. [CrossRef]

20. Jamkhande, P.G.; Ghule, N.W.; Bamer, A.H.; Kalaskar, M.G. Metal nanoparticles synthesis: An overview on methods of preparation, advantages and disadvantages, and applications. J. Drug Deliv. Sci. Technol. 2019, 53, 101174. [CrossRef]

21. Wu, Z.G.; Munoz, M.; Montero, O. The synthesis of nickel nanoparticles by hydrazine reduction. Adv. Powder Technol. 2010, 21, 165-168. [CrossRef]

22. Chou, L.-H.; Hung, W.-C.; Lee, M.-T. On the Preparation of Nickel Nanoparticles by Chemical Reduction Method: X-ray Absorption Spectroscopy. Mater. Sci. 2016, 22, 305-308. [CrossRef]

23. Mahmoodzade, E.; Meshkani, F.; Rezaei, M.; Rastegarpanah, A. Preparation and improvement of nickel catalyst supported ordered mesoporous spherical silica for thermocatalytic decomposition of methane. J. Energy Inst. 2020, 93, 2488-2496. [CrossRef]

24. Ádám, A.A.; Szabados, M.; Varga, G.; Papp, Á.; Musza, K.; Kónya, Z.; Kukovecz, Á.; Sipos, P.; Pálinkó, I. Ultrasound-Assisted Hydrazine Reduction Method for the Preparation of Nickel Nanoparticles, Physicochemical Characterization and Catalytic Application in Suzuki-Miyaura Cross-Coupling Reaction. Nanomaterials 2020, 10, 632. [CrossRef]

25. Liu, G.; Zhao, N.; Shi, C.; Liu, E.; Fang, H.; Ma, L. In-situ synthesis of graphene decorated with nickel nanoparticles for fabricating reinforced 6061Al matrix composites. Mater. Sci. Eng. A 2017, 699, 185-193. [CrossRef]

26. Sagadevan, S.; Chowdhury, Z.Z.; Rafique, R.F. Preparation and Characterization of Nickel ferrite Nanoparticles via Coprecipitation Method. Mater. Res. 2018, 21, e20160533. [CrossRef]

27. Ragupathi, C.; Vijaya, J.J.; Kennedy, L.J. Preparation, characterization and catalytic properties of nickel aluminate nanoparticles: A comparison between conventional and microwave method. J. Saudi Chem. Soc. 2017, 21, S231-S239. [CrossRef]

28. Guillén-Bonilla, H.; Olvera-Amador, M.D.L.L.; Casallas-Moreno, Y.L.; Guillén-Bonilla, J.T.; Guillén-Bonilla, A.; Gildo-Ortiz, L.; Morán-Lázaro, J.P.; Santoyo-Salazar, J.; Rodríguez-Betancourtt, V.M. Synthesis and characterization of nickel antimonate nanoparticles: Sensing properties in propane and carbon monoxide. J. Mater. Sci. Mater. Electron. 2019, 30, 6166-6177. [CrossRef]

29. Ahghari, M.R.; Soltaninejad, V.; Maleki, A. Synthesis of nickel nanoparticles by a green and convenient method as a magnetic mirror with antibacterial activities. Sci. Rep. 2020, 10, 12627. [CrossRef] 
30. Krebsz, M.; Kótai, L.; Sajó, I.E.; Váczi, T.; Pasinszki, T. Carbon Microsphere-Supported Metallic Nickel Nanoparticles as Novel Heterogeneous Catalysts and Their Application for the Reduction of Nitrophenol. Molecules 2021, 26, 5680. [CrossRef]

31. Ádám, A.A.; Szabados, M.; Polyákovics, Á.; Katalin, M.; Zoltán, K.; Ákos, K.; Pál, S.; István, P. The synthesis and use of nano nickel catalysts. J. Nanosci Nanotechno 2019, 19, 453-458. [CrossRef] [PubMed]

32. Song, X.; Gao, L. Facile Route to Nanoporous $\mathrm{NiO}$ Structures from the $\alpha-\mathrm{Ni}(\mathrm{OH})_{2} /$ EG Precursor and Application in Water Treatment. J. Am. Ceram. Soc. 2008, 91, 4105-4108. [CrossRef]

33. El-Sayed, K.; Mohamed, M.B.; Hamdy, S.; Ata-Allah, S.S. Effect of synthesis methods with different annealing temperatures on micro structure, cations distribution and magnetic properties of nano-nickel ferrite. J. Magn. Magn. Mater. 2017, 423, 291-300. [CrossRef]

34. Cai, X.; Cui, X.; Zu, L.; Zhang, Y.; Gao, X.; Lian, H.; Liu, Y.; Wang, X. Ultra High Electrical Performance of Nano Nickel Oxide and Polyaniline Composite Materials. Polymers 2017, 9, 288. [CrossRef]

35. Feng, F.; Shang, Z.; Wang, L.; Zhang, X.; Liang, X.; Wang, Q. Structure-sensitive hydro-conversion of oleic acid to aviation-fuelrange-alkanes over alumina-supported nickel catalyst. Catal. Commun. 2020, 134, 105842. [CrossRef]

36. Su, Z.; Tao, J.; Xiang, J.; Zhang, Y.; Su, C.; Wen, F. Structure evolution and microwave absorption properties of nickel nanoparticles incorporated carbon spheres. Mater. Res. Bull. 2016, 84, 445-448. [CrossRef]

37. Ghimire, P.P.; Gao, M.; Jaroniec, M. Amino acid-assisted synthesis of porous graphitic carbon spheres with highly dispersed Ni nanoparticles. Carbon 2019, 153, 206-216. [CrossRef]

38. Wu, Q.; Li, W.; Tan, J.; Nan, X.; Liu, S. Hydrothermal synthesis of magnetic mesoporous carbon microspheres from carboxymethylcellulose and nickel acetate. Appl. Surf. Sci. 2015, 332, 354-361. [CrossRef]

39. Cui, Y.; Kang, W.; Qin, L.; Ma, J.; Liu, X.; Yang, Y. Ultrafast synthesis of magnetic hollow carbon nanospheres for the adsorption of quinoline from coking wastewater. New J. Chem. 2020, 44, 7490-7500. [CrossRef]

40. Cui, Y.; Qin, L.; Kang, W.; Ma, J.; Yang, Y.; Liu, X. Magnetic carbon nanospheres: Synthesis, characterization, and adsorbability towards quinoline from coking wastewater. Chem. Eng. J. 2020, 382, 122995. [CrossRef]

41. Mao, J.; Wu, Q.; Tao, F.; Xu, W.; Hong, T.; Dong, Y. Facile fabrication of porous BiVO4 hollow spheres with improved visible-light photocatalytic properties. RSC Adv. 2020, 10, 6395-6404. [CrossRef]

42. Sharma, S.; Umar, A.; Mehta, S.K.; Ibhadon, A.O.; Kansal, S.K. Solar light driven photocatalytic degradation of levofloxacin using $\mathrm{TiO}_{2} /$ Carbon-dot nanocomposites. N. J. Chem. 2018, 42, 7445-7456. [CrossRef]

43. Yin, Y.; Zhou, S.; Min, C.; Wu, L. Preparation of rattle-type magnetic mesoporous carbon spheres and their highly efficient adsorption and separation. J. Colloid Interface Sci. 2011, 361, 527-533. [CrossRef] [PubMed]

44. Dong, Y.; Tao, F.; Wang, L.; Lan, M.; Zhang, J.; Hong, T. One-pot preparation of hierarchical $\mathrm{Cu}_{2} \mathrm{O}$ hollow spheres for improved visible-light photocatalytic properties. RSC Adv. 2020, 10, 22387-22396. [CrossRef]

45. Maneechakr, P.; Karnjanakom, S. Facile utilization of magnetic $\mathrm{MnO}_{2} @ \mathrm{Fe}_{3} \mathrm{O}_{4} @$ sulfonated carbon sphere for selective removal of hazardous $\mathrm{Pb}(\mathrm{II})$ ion with an excellent capacity: Adsorption behavior/isotherm/kinetic/thermodynamic studies. J. Environ. Chem. Eng. 2021, 9, 106191. [CrossRef]

46. Zong, P.; Cheng, Y.; Wang, S.; Wang, L. Simultaneous removal of Cd(II) and phenol pollutions through magnetic graphene oxide nanocomposites coated polyaniline using low temperature plasma technique. Int. J. Hydrogen Energy 2020, 45, 20106-20119. [CrossRef]

47. Huang, X.; Nan, Z. Synergetic adsorption and photo-Fenton degradation of methylene blue by $\mathrm{ZnFe}_{2} \mathrm{O}_{4} / \mathrm{SiO}_{2}$ magnetic doublemesoporous-shelled hollow spheres. Environ. Technol. 2020, 42, 3218-3230. [CrossRef]

48. Majhia, D.; Patra, B.N. Polyaniline and sodium alginate nanocomposite: A pH-responsive adsorbent for the removal of organic dyes from water. RSC Adv. 2020, 10, 43904-43914. [CrossRef]

49. Ma, J.; Sun, S.; Chen, K. Facile and scalable synthesis of magnetite/carbon adsorbents by recycling discarded fruit peels and their potential usage in water treatment. Bioresour. Technol 2017, 233, 110-115. [CrossRef]

50. Zhang, M.; Yao, Q.; Lu, C.; Li, Z.; Wang, W. Layered Double Hydroxide-Carbon Dot Composite: High-Performance Adsorbent for Removal of Anionic Organic Dye. ACS Appl. Mater. Interfaces 2014, 6, 20225-20233. [CrossRef]

51. Bouchenafa-Saib, N.; Chennouf-Abdellatif, Z.; Cheknane, B.; Zermane, F.; Gaigneaux, E.M.; Mohammedi, O. Equilibrium and kinetic studies of methyl orange and Rhodamine B adsorption onto prepared activated carbon based on synthetic and agricultural wastes. Desalin. Water Treat. 2017, 67, 284-291.

52. Dalal, C.; Garg, A.K.; Sonkar, S.K. Carboxylic acid-terminated carbon nanoflakes for selective adsorption of water-soluble cationic dyes. ACS Appl. Nano Mater. 2021, 4, 5611-5620. [CrossRef]

53. Zhang, L.; Liu, Y.; Wang, S.; Liu, B.; Peng, J. Selective removal of cationic dyes from aqueous solutions by an activated carbon-based multicarboxyl adsorbent. RSC Adv. 2015, 5, 99618-99626. [CrossRef]

54. Yadav, S.K.; Dhakate, S.; Singh, B.P. Carbon nanotube incorporated eucalyptus derived activated carbon-based novel adsorbent for efficient removal of methylene blue and eosin yellow dyes. Bioresour. Technol. 2021, 344, 126231. [CrossRef] [PubMed]

55. Siddiqui, M.F.; Khan, S.A.; Hussain, D.; Tabrez, U.; Ahamad, I.; Fatma, T.; Alam Khan, T. A sugarcane bagasse carbon-based composite material to decolor and reduce bacterial loads in waste water from textile industry. Ind. Crop. Prod. 2021, 176, 114301. [CrossRef] 
56. Singh, V.P.; Vaish, R. Candle soot coated polyurethane foam as an adsorbent for removal of organic pollutants from water. Eur. Phys. J. Plus 2019, 134, 419. [CrossRef]

57. Hall, K.R.; Eagleton, L.C.; Acrivos, A.; Vermeulen, T. Pore- and Solid-Diffusion Kinetics in Fixed-Bed Adsorption under ConstantPattern Conditions. Ind. Eng. Chem. Fundam. 1966, 5, 212-223. [CrossRef]

58. Weber, T.W.; Chakravorti, R.K. Pore and solid diffusion models for fixed-bed adsorbers. AIChE J. 1974, 20, 228-238. [CrossRef] 